\title{
nature
}

\section{Spanish universities and the obstacles to development}

A viable science base requires a commitment to excellence and imagination that is incompatible with rigidity and cronyism. Spain needs to absorb this lesson if it is to flourish scientifically and economically.

F

ew countries are as well placed to turn modern science to their

economic and social advantage as Spain. On the one hand,

Spain's membership of the European Union should, in principle, allow it to tap into the best that Europe's research laboratories can offer. On the other, it enjoys the long-term prospect of expanding markets in Latin America. Yet a traditionally heavy-handed bureaucracy, the legacy of scientific stagnation during the Franco years, and the side-effects of a strong libertarian backlash when the Franco yoke was lifted, still threaten to hold the country back from exploiting this opportunity to the full. The consequent obstacles to progress are damagingly frustrating to Spain's best scientists who, despite this, continue to support their country's scientific and economic development.

Take the issue of university appointments. Current laws on universities, introduced in 1983, rightly give such institutions considerable freedom in appointing tenured faculty members (previously, these had been appointed centrally). But there is much evidence that the procedure under which such appointments are made, in particular the make-up of five-member appointments boards, two members of which come from the university involved, can remain excessively influenced by non-academic considerations. The concern is that the autonomy of universities has allowed the appointments process to become dominated by mutual self-interest operating through selfsustaining social networks - in other words, 'cronyism'.

The issue has been highlighted by charges brought by one astrophysicist against the University of Salamanca, who had returned to Spain - ironically in response to a government appeal — after working for eight years in Germany (see page 712). The astrophysicist claims that he was inappropriately, and illegally, rejected for a faculty appointment, despite the superiority of his scientific qualifications. In drawing attention to this case, Nature is not seeking to make any judgement on the validity of the university's decision to award two different posts, for which the astrophysicist had applied, to internal candidates. Nor, indeed, is the case necessarily different from thousands of similar but less formal complaints that cronyism overshadows scientific performance in the appointments process.

The situation in Spain is by no means unique, but that should not make it any more acceptable. To its credit, the current administration in Madrid has shown itself aware of the problem. Proposed changes to university laws currently under consideration would alter the make-up of appointments committees, requiring at least four of the five members to come from other universities (selected at random). Such a move would be a welcome challenge to the 'cronyist' temptations.

But the problem goes deeper than voting procedures. Social networks will always find ways to flourish, whatever is done to limit their effectiveness. And changing the appointments process on its own will not address the second major problem facing universities in Spain (and elsewhere): the intellectual sclerosis created by a broad system of tenure that requires little accountability from researchers, after they have crossed initial hurdles, for the rest of their working lives. The trick is to find a way of improving the situation that does not undermine the commitment to long-term goals on which the health of a growing science base depends.

The two problems need to be addressed together. Again, this appears to be recognized by many of those government officials who are responsible for the health of the nation's research base, for example in the proposal that universities provide four-year teaching contracts. It seems to be less accepted in wider political circles, where those who enjoy the privileges and security of the current arrangements - and who would be directly threatened by any significant changes — can often find substantial support. But change is essential if Spain is to achieve its full scientific and technological potential. Already some institutions, such as the nascent National Centre for Cancer Research in Madrid, are demonstrating that alternative arrangements are possible; hopefully, a high scientific output from such 'experiments' will show that they are also desirable. Spain's politicians should give them close attention.

\section{Kemp's cultures}

A series that ends this week should inspire not only appreciation of images but also a desire to communicate.

rresistibly and in occasionally peremptory fashion, science has, in recent years, embedded itself ever deeper into everyday culture. One can reasonably assume that this infiltration will grow as science significantly extends and deepens our understanding of just what we are.

Visually, that cultural permeation can be witnessed at several levels. Citizens are surrounded by images, often taken out of scientific context, with values ranging from the ephemeral to the icon with an impact that resonates for decades. At a deeper level, scientific ideas and perspectives are absorbed by artists and significantly enrich their portrayals or creative extensions of the world.
For over a year, Martin Kemp has treated readers of Nature, week by week, to a seemingly endless celebration of diverse and often beautiful artistic and scientific images and the (respectively) scientific and artistic impulses that can be traced within them. But the end has finally come (page 727). To judge by the author's electronic mailbox, readers have been much stimulated. They will be pleased to know that he will continue to contribute regularly, albeit less frequently, in future. Meanwhile, researchers might consider the ever more important need to communicate their science not only to their peers but also in ways that others can appreciate and that artists in particular, occasionally but valuably, can creatively absorb. 